\title{
Quantitative Ultrasound Spectroscopy
}

National Cancer Institute

\section{Source}

National Cancer Institute. Quantitative Ultrasound Spectroscopy. NCI Thesaurus. Code C127309.

An application of conventional frequency spectroscopic ultrasound data that uses ultrasound backscattered radiofrequency (RF) signals to determine the bioacoustic properties of the underlying tissue for characterizing its microstructure. 